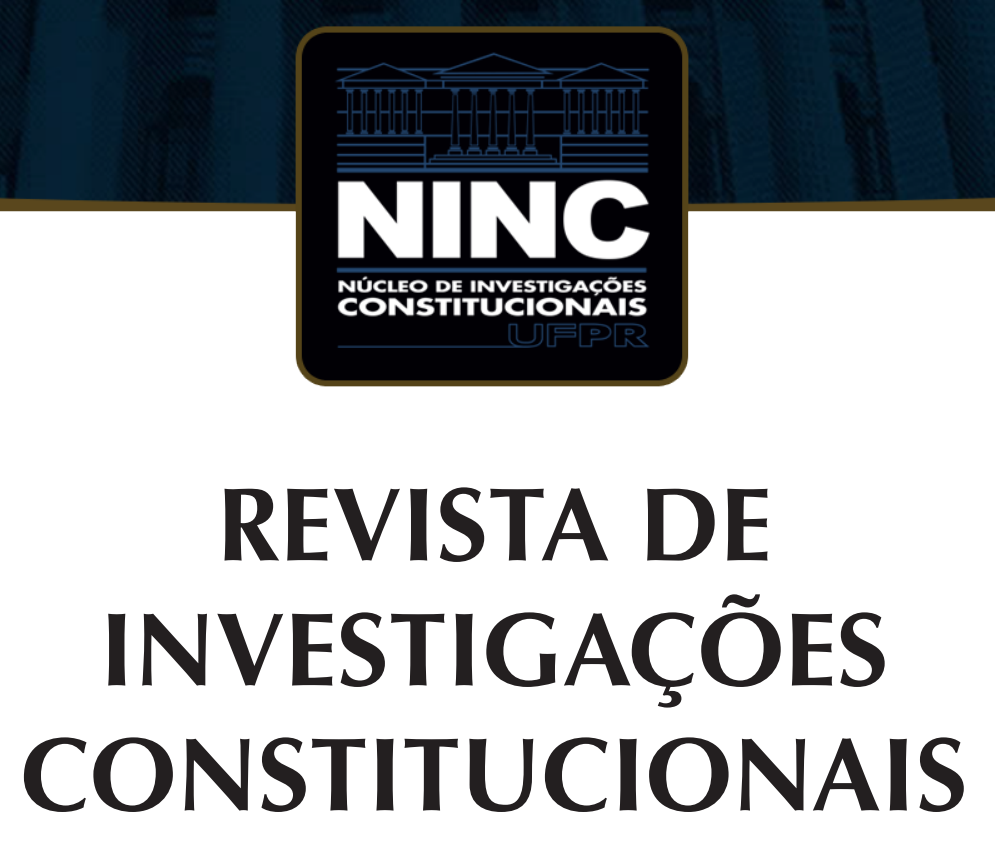

JOURNAL OF CONSTITUTIONAL RESEARCH

vol. 6 | n. 1 | janeiro/abril 2019 | ISSN 2359-5639 | Periodicidade quadrimestral Curitiba | Núcleo de Investigações Constitucionais da UFPR | www.ninc.com.br 


\title{
Os paradoxos da deliberação judicial colegiada
}

\section{The paradoxes of collegial judicial deliberation}

\author{
GUILHERME DA FRANCA COUTO FERNANDES DE ALMEIDA ${ }^{\mathrm{I}, *}$ \\ I Pontifícia Universidade Católica do Rio de Janeiro (Brasil) \\ guilherme.almeida@fgv.br \\ https://orcid.org/0000-0002-9134-9843

\section{PEDRO HENRIQUE VEIGA CHRISMANN ${ }^{\mathrm{II}, * *}$}

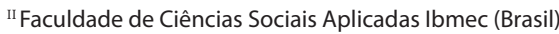 \\ pedrochrismann@gmail.com \\ http://orcid.org/0000-0002-2908-4936 \\ Recebido/Received: 25.01.2018 / January $25^{\text {th }}, 2018$ \\ Aprovado/Approved: 30.10 .2018 / October 30 ${ }^{\text {th }}, 2018$
}

\section{Resumo}

Em alguns casos, há pouca convergência entre os Ministros com relação aos fundamentos de uma dada decisão do Supremo Tribunal Federal. Há vezes em que o tribunal sequer forma maioria com relação à razão de decidir, tornando extremamente difícil a aplicação de seus precedentes. Argumentamos que parte da causa desse problema está na aplicabilidade dos teoremas da impossibilidade de Arrow e de List e Pettit às decisões colegiadas judiciais. Ademais, veremos que embora esse sempre tenha sido (e provavelmente será) o caso, o problema se torna muito mais grave quando se aumentam as opções de fundamentação disponíveis ao juiz, como acontece em função da adoção da causa de pedir aberta nas ações de controle concentrado de constitucionalidade, nos

\section{Abstract}

In some cases, there is little convergence among Justices with regards to the reasons underlying a given Supremo Tribunal Federal's decision. Sometimes, there isn't even a majoritarian ratio decidendi, making it very difficult to use some decisions as precedent. We argue that part of the problem is owed to the susceptibility of collegial judicial decisions to the impossibility theorems postulated by Arrow and List and Pettit. Moreover, we'll see that even though this may have always been (and will be) the case, the problem is made much more severe when there is an increase in the number of accepted reasons from the judge's perspective, which happens as a result of open-ended causa petendi in the abstract model of judicial review, under underdetermined authoritative texts or when judge's apply techniques

Como citar esse artigo/How to cite this article: ALMEIDA, Guilherme da Franca Couto Fernandes de; CHRISMANN, Pedro Henrique Veiga. Deliberação judicial colegiada: aspectos problemáticos. Revista de Investigações Constitucionais, Curitiba, vol. 6, n. 1, p. 165-188, jan./abr. 2019. DOI: 10.5380/rinc.v6i1.57578.

" Doutorando e Mestre em Teoria do Estado e Direito Constitucional pela Pontifícia Universidade Católica do Rio de Janeiro (Rio de Janeiro-RJ, Brasil). Graduado em Direito pela Universidade Federal do Rio de Janeiro (UFRJ). Coordenador do projeto Supremo em Números, da FGV Direito Rio. E-mail: guilherme.almeida@fgv.br.

${ }^{* *}$ Professor adjunto da Faculdade de Ciências Sociais Aplicadas Ibmec (Rio de Janeiro-RJ, Brasil). Doutor e mestre em Teoria do Estado e Direito Constitucional pela Pontifícia Universidade Católica do Rio de Janeiro (Rio de Janeiro-RJ, Brasil). Graduado em Direito pela Universidade Federal do Rio de Janeiro (UFRJ).E-mail: pedrochrismann@gmail.com. 
casos de textos menos determinados ou na aplicação de técnicas como a declaração de nulidade parcial sem redução de texto.

Palavras-chave: Supremo Tribunal Federal; tomada de decisões; fundamentação racional; Teorema de Arrow; Teorema de List e Pettit. such as partial declaration of unconstitutionality without text suppression.

Keywords: Supremo Tribunal Federal; decision-making; Rational Choice Theory; Arrow's Theorem; List and Pettit's Theorem.

\section{SUMÁRIO}

1. Introdução; 2. O paradoxo da votação; 3. Arrow e os tribunais; 4. Paradoxo doutrinário; 5. Conclusão; 6. Referências.

\section{INTRODUÇÃO}

É possível identificar um problema na jurisprudência do Supremo Tribunal Federal: nem sempre a Corte é clara quanto aos fundamentos de suas decisões ${ }^{1}$. Mesmo quando há uma decisão amplamente majoritária (ou unânime), não é geralmente possível identificar um fundamento singular que possa ser considerado vencedor. Isto ocorre tendo em vista que cada um dos ministros apresenta suas próprias razões e fundamentos ${ }^{2}$. Esse é o fenômeno que os professores Marcelo Brando e Fábio Leite ${ }^{3}$ chamam de "dispersão de fundamentos"4.

Em um caso normal, no qual só o que está em julgamento é o direito de um jurisdicionado específico, essa questão pode parecer pouco importante. Afinal, independentemente das razões para que ele perca/ganhe, o fato é que ele perdeu/ganhou, e terá ou não terá a proteção jurisdicional do direito que postulava. A questão ganha outros contornos, porém, quando consideramos que a jurisprudência, ou o precedente ${ }^{5}$, pode ter aplicação para além da esfera pessoal daquele jurisdicionado específico ${ }^{6}$.

\footnotetext{
${ }^{1}$ Ver, entre outros, BRANDO, Marcelo Santini; LEITE, Fábio Carvalho. Dispersão de fundamentos no Supremo Tribunal Federal. Revista Direito, Estado e Sociedade, Rio de Janeiro, n. 48, p. 139-166, jan./jun. 2016.

${ }^{2}$ Vide VOJVODIC, Adriana de Moraes, MACHADO, Ana Mara França e CARDOSO, Evorah Lusci Costa. Escrevendo um romance, primeiro capítulo: precedentes e processo decisório no STF. Revista Direito GV, São Paulo, vol. 5, n. 1, 2009, pp. 21-44, sobre a ADI 3.510.

${ }^{3}$ Doravante Brando e Leite.

${ }^{4}$ BRANDO, Marcelo Santini e LEITE, Fábio Carvalho. Dispersão de fundamentos no Supremo Tribunal Federal. Revista Direito, Estado e Sociedade, n 48, 2016, p. 141.

${ }^{5}$ Seguindo a distinção tradicional, entende-se jurisprudência como um coletivo de decisões do tribunal em um mesmo sentido, enquanto precedente pode ser interpretado como uma decisão em determinada direção que serve como um guia para decisões jurídicas futuras.

${ }^{6}$ Destaque-se, ainda, que a aplicação dos precedentes no Direito brasileiro vem sendo ampliada a cada dia, o que torna ainda mais dramática a necessidade de clareza nos motivos para a construção das decisões dos tribunais, principalmente em se tratando de cortes superiores. Para uma análise crítica da construção e do uso de precedentes no Brasil, ver CHRISMANN, Pedro Henrique Veiga. Julieta não está pronta para ser Montecchio - A união das famílias jurídicas e a necessidade de uma nova metodologia do direito preocupada com precedentes. Revista de Direito Brasileira, São Paulo, vol. 14, n. 6, p. 03-17, maio/ago. 2016.
} 
Pode ser que outras pessoas que se encontrem em uma situação jurídica semeIhante àquela estejam acompanhando aquele julgamento com a finalidade de prever o futuro de seu próprio direito. Se, mais adiante, esse novo jurisdicionado ganhar a tutela jurisdicional de seu direito, que é semelhante em todos os aspectos relevantes ao direito do jurisdicionado ${ }^{7}$ desse caso pregresso, que, digamos, perdeu sua ação, parece ter sido cometida uma injustiça. Logo, ao menos em geral, é desejável que as decisões judiciais sejam transparentes quanto a sua fundamentação ${ }^{8}$.

Em sede de controle de constitucionalidade, há pouca dúvida sobre a importância da fundamentação de decisões. Os julgados têm eficácia erga omnes, sendo imediatamente aplicáveis a todos os jurisdicionados. Desta forma, é difícil imaginar que decisões desse tipo possam ser legítimas, democráticas e até mesmo justas, a depender do conceito de justiça que se empregue, quando pouco fundamentadas ${ }^{9}$. Não vamos enfrentar, portanto, as polêmicas existentes a respeito do papel exato que a fundamentação exerce na fixação dos precedentes ou no caráter vinculante das decisões do STF. Pressupomos que, de uma maneira ou de outra, a fundamentação das decisões é importante para a operação do direito judicial.

Em alguns casos, porém, o problema é ainda mais grave do que aquele que é objeto da discussão tradicional sobre a importância dos precedentes. Esses casos surgem a partir da possibilidade de interpretação conforme e/ou declaração de nulidade parcial sem redução de texto. Barroso, ao comentar a interpretação conforme, afirma que ela é um gênero, da qual a declaração de nulidade parcial sem redução de texto é uma espécie, que "consiste na exclusão de uma determinada interpretação possível

\footnotetext{
${ }^{7}$ Um ponto que pode ser levantado é que a própria identificação dos aspectos normativamente relevantes está condicionada à fundamentação da decisão. Quando não há um esclarecimento sobre as razões que sustentam o julgado, há a possibilidade maior de um espaço de interpretação sobre o âmbito de aplicação do precedente. Ver CHRISMANN, Pedro Henrique Veiga. Julieta não está pronta para ser Montecchio - A união das famílias jurídicas e a necessidade de uma nova metodologia do direito preocupada com precedentes. Revista de Direito Brasileira, São Paulo, vol. 14, n. 6, p. 03-17, maio/ago. 2016.

${ }^{8}$ Assumimos esse ponto como não problemático, na esteira de VOJVODIC, Adriana de Moraes; MACHADO, Ana Mara França; CARDOSO, Evorah Lusci Costa. Escrevendo um romance, primeiro capítulo: precedentes e processo decisório no STF. Revista Direito GV, São Paulo, vol. 5, n. 1, p. 21-44, jan./jun. 2009; BRANDO, Marcelo Santini; LEITE, Fábio Carvalho. Dispersão de fundamentos no Supremo Tribunal Federal. Revista Direito, Estado e Sociedade, Rio de Janeiro, n. 48, p. 139-166, jan./jun. 2016. Existe ampla discussão na literatura sobre os benefícios e malefícios da doutrina do precedente. Para discussões mais detalhadas sobre o assunto, ver ALEXANDER, Larry; SHERWIN, Emily. Demystifying Legal Reasoning. Cambridge: Cambridge University Press, 2008; SCHAUER, Frederick. Precedent. In: MARMOR, Andrei (Org.) The Rouledge Companion to Philosophy of Law. New York: Routledge, 2012; SCHAUER, Frederick. Thinking like a lawyer. Cambridge: Harvard University Press, 2009. De qualquer modo, ainda que discordemos do argumento a favor do uso de precedentes, devemos observar que a CRFB/88, em seu art. 93, IX, estabeleceu a obrigatoriedade de fundamentação das decisões judiciais, de forma que é natural imaginar que os juízes e tribunais brasileiros têm uma obrigação de produzir decisões fundamentadas.

${ }^{9}$ BRANDO, Marcelo Santini; LEITE, Fábio Carvalho. Dispersão de fundamentos no Supremo Tribunal Federal. Revista Direito, Estado e Sociedade, Rio de Janeiro, n. 48, p. 139-166, jan./jun. 2016; SILVA, Virgílio Afonso da. Deciding without deliberating. International Journal of Constitutional Law, vol. 11, n. 3, p. 557-584, jul./ sept. 2013.
} 
da norma - geralmente a mais óbvia - e na afirmação de uma interpretação alternativa compatível com a Constituição"10.

Uma situação em particular, que se enquadra na definição de Barroso, causa preocupação com relação à dispersão de fundamentos. Digamos que o STF concorde, em controle concentrado de constitucionalidade, sobre o julgamento correto: declarar a nulidade parcial sem redução de texto. Essa decisão, inclusive, pode se dar de forma unânime. Nada garante, porém, que a "interpretação alternativa compatível com a Constituição" seja a mesma para todos os ministros. Pode ser que não se forme sequer uma maioria com relação a essa leitura.

Imaginemos o seguinte cenário: o STF é provocado a julgar a constitucionalidade da lei $L$. Todos os ministros concordam que $L$ é constitucional, se lida de determinada maneira, mas nenhum ministro concorda com nenhum dos outros sobre que interpretação é essa. Um ministro propõe $\mathrm{I}_{1}$, outro propõe $\mathrm{I}_{2}$ e, ao final do último voto, temos 11 interpretações diferentes $\left(I_{1} \ldots I_{11}\right)$ que tornam $L$ constitucional. A decisão é unânime no sentido de que a lei é constitucional, mas não apresenta qualquer conteúdo capaz de guiar a atuação dos jurisdicionados e dos futuros aplicadores do direito. Esse caso, como veremos, é extremamente relevante.

A questão colocada por Brando e Leite ${ }^{11}$ é bastante simples: como prevenir esse problema? Os autores avaliam 3 possíveis causas do problema: 1) a indeterminação relativa do texto constitucional; 2) a causa de pedir aberta e 3) a regra de decisão por maioria simples. $O$ foco normativo dos autores é defender a substituição do mecanismo de votação do STF (3) por um que conte os votos a favor de cada fundamento ${ }^{12}$.

\footnotetext{
${ }^{10}$ BARROSO, Luís Roberto. 0 controle de constitucionalidade no direito brasileiro: exposição sistemática da doutrina e análise crítica da jurisprudência. 6. ed. São Paulo: Saraiva, 2012, p. 145. Uma observação similar se encontra em SILVA, Virgílio Afonso da. Deciding without deliberating. International Journal of Constitutional Law, vol. 11, n. 3, p. 557-584, jul./sept. 2013, p. 573, nota de rodapé 49 e texto, onde o autor aponta para a possibilidade de resultados não binários em conexão com o uso da interpretação conforme. Um dos revisores anônimos apontou para obra anterior do autor (SILVA, Virgílio Afonso. Interpretação conforme a constituição: entre a trivialidade e a centralização judicial. Revista Direito GV, vol. 2, n. 1, p. 191-210, 2006.) para argumentar que a caracterização que fizemos da interpretação conforme à constituição e da declaração de nulidade parcial sem redução de texto se baseava em um equívoco conceitual. Discordamos da crítica: o STF rotineiramente usa os conceitos no sentido indicado no texto com o efeito que discutimos. Esse parece ter sido o caso, por exemplo, na ADPF 132. Ademais, nada no artigo mencionado conflita com as afirmações centrais do presente trabalho, funcionando muito mais como uma crítica (pertinente) aos métodos interpretativos aplicados pela corte do que como uma descrição de suas práticas discursivas: mesmo que concordemos com o autor e reservemos nossa crítica a apenas um dos dois fenômenos identificados, ainda estaremos diante de um problema real.

${ }^{11}$ BRANDO, Marcelo Santini; LEITE, Fábio Carvalho. Dispersão de fundamentos no Supremo Tribunal Federal. Revista Direito, Estado e Sociedade, Rio de Janeiro, n. 48, p. 139-166, jan./jun. 2016.

${ }^{12}$ Guilherme Forma Klafke e Bruna Romano Pretzel comentam en passant que essa parece ter sido a opção do Tribunal Constitucional espanhol. Cf. KLAFKE, Guilherme Forma; PRETZEL, Bruna Romano. Processo decisório no Supremo Tribunal Federal: aprofundando o diagnóstico das onze ilhas. Revista de Estudos Empíricos em Direito, v. 1, p. 89-104, 2014.
} 
No presente artigo, pretende-se analisar, em primeiro lugar, a sugestão da mudança da regra de votação, mostrando que a deliberação no âmbito do STF é uma instância do teorema de Arrow ${ }^{13}$. Se esse é o caso, a mudança da regra de votação não parece ser suficiente para resolver o problema. Por outro lado, mudar a regra de votação implica um conjunto de problemas ligeiramente diferente, advindos da incidência do teorema da impossibilidade de List e Pettit ${ }^{14}$. Por fim, será demostrado como os outros dois fatores apontados por Brando e Leite ${ }^{15}$, quando vistos à luz dos teoremas discutidos, parecem indicar soluções mais claras para o problema ${ }^{16}$.

O artigo será estruturado da seguinte forma: no item 2, oferecemos uma breve descrição do que constitui o paradoxo da votação e o teorema de Arrow ${ }^{17}$; no item 3, apresentamos um argumento para demonstrar a pertinência do paradoxo e do teorema no caso específico das decisões colegiadas no direito ${ }^{18}$, apontando como o problema inclui a dispersão de fundamentos ${ }^{19}$; no item 4, descreveremos o teorema da impossibilidade postulado por List e Pettit ${ }^{20}$ e como ele representa um problema diferente, embora intimamente relacionado, ao do paradoxo da votação; na conclusão (item 5), pretendemos mostrar que, dados os teoremas da impossibilidade provados pelos autores supra citados, nos resta buscar os arranjos de votação que impliquem uma menor quantidade de casos paradoxais, o que implica reavaliar as outras causas apontadas

\footnotetext{
${ }^{13}$ ARROW, Kenneth Joseph. Social choice and individual values. New York: Jon Wiley \& Sons, 1963.

${ }^{14}$ LIST, Christian; PETTIT, Philip. Aggregating sets of judgement: an impossibility result. Economics and Philosophy, Cambridge, vol. 18, n. 1, p. 89-110, apr. 2002.

${ }^{15}$ BRANDO, Marcelo Santini; LEITE, Fábio Carvalho. Dispersão de fundamentos no Supremo Tribunal Federal. Revista Direito, Estado e Sociedade, Rio de Janeiro, n. 48, p. 139-166, jan./jun. 2016.

${ }^{16}$ Da mesma forma, muito embora a valorização da "cultura do precedente", defendida por VOJVODIC, Adriana de Moraes; MACHADO, Ana Mara França; CARDOSO, Evorah Lusci Costa. Escrevendo um romance, primeiro capítulo: precedentes e processo decisório no STF. Revista Direito GV, São Paulo, vol. 5, n. 1, p. 21-44, jan./jun. 2009, possa ser positiva, ela também não é capaz de resolver o problema da dispersão de fundamentos. Não só por não atuar sobre as causas do problema, como também porque a dispersão de fundamentos também existe na jurisprudência norte-americana (ver MEYERSON, Michael. The irrational Supreme Court. Nebraska Law Review, Nebraska, vol. 84, n. 3, p. 895-961, jul./sept. 2006; EASTERBROOK, Frank. Ways of criticizing the court. Harvard Law Review, Cambridge, vol. 95, n. 4, p. 802-832, feb. 1982), na qual dificilmente se argumentaria que não vigora uma cultura de valorização ao precedente.

${ }^{17}$ ARROW, Kenneth Joseph. Social choice and individual values. New York: Jon Wiley \& Sons, 1963; ARROW, Kenneth Joseph. A difficulty in the concept of social welfare. Journal of Political Economy, Chicago, vol. 58, n. 4, p. 328-346. 1950.

${ }^{18}$ MEYERSON, Michael. The irrational Supreme Court. Nebraska Law Review, Nebraska, vol. 84, n. 3, p. 895-961, jul./sept. 2006; EASTERBROOK, Frank. Ways of criticizing the court. Harvard Law Review, Cambridge, vol. 95, n. 4, p. 802-832, feb. 1982.

${ }^{19}$ BRANDO, Marcelo Santini; LEITE, Fábio Carvalho. Dispersão de fundamentos no Supremo Tribunal Federal. Revista Direito, Estado e Sociedade, Rio de Janeiro, n. 48, p. 139-166, jan./jun. 2016; VOJVODIC, Adriana de Moraes; MACHADO, Ana Mara França; CARDOSO, Evorah Lusci Costa. Escrevendo um romance, primeiro capítulo: precedentes e processo decisório no STF. Revista Direito GV, São Paulo, vol. 5, n. 1, p. 21-44, jan./jun. 2009.

${ }^{20}$ LIST, Christian; PETTIT, Philip. Aggregating sets of judgement: an impossibility result. Economics and Philosophy, Cambridge, vol. 18, n. 1, p. 89-110, apr. 2002.
} 
por Brando e Leite ${ }^{21}$, a saber: 1) a indeterminação relativa do texto constitucional; e 2) a incidência da causa de pedir aberta.

\section{O PARADOXO DA VOTAÇÃO E O TEOREMA DE ARROW}

Suponhamos que três juízes tenham que decidir uma apelação. Cada um deles só tem duas opções com relação ao julgamento: (1) a apelação é provida ou (2) a apelação é improvida ${ }^{22}$. Vamos supor, ainda, que todos os três juízes concordem com (1) e pensem que a apelação deve ser provida. Nesse caso, não temos dúvidas quanto ao resultado do julgamento: a apelação foi provida.

Imaginemos, porém, que as razões para que cada um dos três juízes tenha provido a apelação sejam radicalmente diferentes. É possível que os juízes 1, 2 e 3 tenham decidido como fundamento $F$, respectivamente, que: $\left(F_{1}\right)$ a sentença de primeiro grau tenha sido proferida por juiz incompetente; $\left(F_{2}\right)$ o apelante tinha razão no mérito; e $\left(F_{3}\right)$ o apelado não apresentou contrarrazões. Por fim, pressuponhamos que cada um dos três juízes esteja totalmente decidido a manter sua decisão. Como resolver a questão?

Uma das maneiras de resolver o impasse entre os três juízes é aquela postulada por Condorcet ${ }^{23}$ : cada um deve fazer uma ordem de preferência dos três fundamentos que foram levantados ${ }^{24}$. Assim, certamente, saberemos qual o fundamento preferido

${ }^{21}$ BRANDO, Marcelo Santini; LEITE, Fábio Carvalho. Dispersão de fundamentos no Supremo Tribunal Federal. Revista Direito, Estado e Sociedade, Rio de Janeiro, n. 48, p. 139-166, jan./jun. 2016.

${ }^{22}$ Naturalmente, é possível que ela seja parcialmente provida, mas para fins de simplificação, imaginemos que parcialmente provida conte como uma instância de provimento. O mesmo tipo de simplificação é sistematicamente realizado pela literatura que trata do tema. Ver MEYERSON, Michael. The irrational Supreme Court. Nebraska Law Review, Nebraska, vol. 84, n. 3, p. 895-961, jul./sept. 2006; EASTERBROOK, Frank. Ways of criticizing the court. Harvard Law Review, Cambridge, vol. 95, n. 4, p. 802-832, feb. 1982; KORNHAUSER, Lewis A.; SAGER, Lawrence G. Unpacking the court. The Yale Law Journal, Danvers, vol. 96, n. 1, p. 82-117. 1986.

${ }^{23}$ Ver ARROW, Kenneth Joseph. Social choice and individual values. New York: Jon Wiley \& Sons, 1963; MEYERSON, Michael. The irrational Supreme Court. Nebraska Law Review, Nebraska, vol. 84, n. 3, p. 895-961, jul./ sept. 2006; EASTERBROOK, Frank. Ways of criticizing the court. Harvard Law Review, Cambridge, vol. 95, n. 4, p. 802-832, feb. 1982.

${ }^{24} \mathrm{~A}$ maioria das exposições começa pressupondo a vantagem da votação de Condorcet sobre a votação "padrão", em que cada juiz vota apenas uma vez e apenas em seu fundamento favorito. KORNHAUSER, Lewis A.; SAGER, Lawrence G. Unpacking the court. The Yale Law Journal, Danvers, vol. 96, n. 1, p. 82-117. 1986, porém, apresenta argumentos que mostram uma incompreensão desse fato, razão pela qual pensamos ser necessária a demonstração anterior de que um sistema de votação simples não resolve o problema. De fato, quando autores como Easterbrook (EASTERBROOK, Frank. Ways of criticizing the court. Harvard Law Review, Cambridge, vol. 95, n. 4, p. 802-832, feb. 1982) descrevem o paradoxo da votação judicial como uma instância de votação de Condorcet, isso não representa problema algum. O problema já existe antes da votação comum, sendo certo que a aplicação do sistema de Condorcet reduz o número de vezes em que ficaremos sem um vencedor preferido pelo grupo. É por isso que a crítica de Kornhauser e Sager não faz sentido. Quando dizem que "...although courts might adopt a mechanism that did produce a complete ranking of the alternatives, it seems silly to do so when such a choice has no apparent benefits and plunges one into the antinomies of Arrow's theorem" (KORNHAUSER, Lewis A.; SAGER, Lawrence G. Unpacking the court. The Yale Law Journal, Danvers, vol. 96, n. 1, p. 82-117. 1986 p. 110. Observação repetida em p. 114), os autores erram ao ignorarem que Condorcet produz mais resultados satisfatórios do que a votação normal. 
pelo órgão julgador, não? Suponhamos que a ordem de preferência dos três juízes seja a seguinte:

\begin{tabular}{|c|c|c|c|c|}
\hline \multirow{4}{*}{$\begin{array}{l}\frac{\sigma}{U} \\
\frac{C}{U} \\
\frac{U}{U} \\
\frac{U}{U} \\
\frac{U}{U} \\
\frac{1}{2}\end{array}$} & & Juiz 1 & Juiz 2 & Juiz 3 \\
\hline & 10 & $\mathrm{~F}_{1}$ & $\mathrm{~F}_{2}$ & $\mathrm{~F}_{3}$ \\
\hline & 20 & $\mathrm{~F}_{2}$ & $\mathrm{~F}_{3}$ & $\mathrm{~F}_{1}$ \\
\hline & 30 & $\mathrm{~F}_{3}$ & $\mathrm{~F}_{1}$ & $\mathrm{~F}_{2}$ \\
\hline
\end{tabular}

Para determinarmos o vencedor dessa votação, precisamos que cada um dos fundamentos enfrente cada um dos outros fundamentos em uma comparação direta. Assim, poderíamos começar comparando $F_{1}$ e $F_{2}$ : os juízes 1 e 3 classificam $F_{1}$ acima de $F_{2}$. Logo, podemos dizer que o grupo prefere $F_{1}$ a $F_{2}$, tornando $F_{1}$ o vencedor da primeira comparação. Será que $F_{1}$ também é preferido com relação a $F_{3}$ ? Embora o juiz 1 classifique $F_{1}$ acima de $F_{3^{\prime}}$ os juízes 2 e 3 classificam $F_{3}$ acima de $F_{1}$, fazendo de $F_{3}$ o vencedor dessa comparação. $F_{3^{\prime}}$ na sequência deve mostrar que é preferido pelo grupo com relação a $F_{2}$, mas isso não é verdadeiro: $F_{3}$ é o fundamento preferido do juiz 3 , mas os juízes 1 e 2 preferem $F_{2}$ a $F_{3}$. Logo, $F_{2}$ é o vencedor dessa comparação. Mas $F_{2}$ foi o perdedor da primeira comparação, que parecia indicar que $F_{1}$ era preferida pelo grupo sobre $F_{2}$.

Esse é o paradoxo da votação: quando duas ou mais pessoas precisam decidir sobre mais de duas opções, é sempre possível que nenhum resultado seja atingido. Isso acontece porque a ordem de preferência é cíclica ${ }^{25}$ :

\footnotetext{
${ }^{25}$ Toda essa explicação, incluindo as tabelas, é praticamente uma reprodução das explicações oferecidas por MEYERSON, Michael. The irrational Supreme Court. Nebraska Law Review, Nebraska, vol. 84, n. 3, p. 895-961, jul./sept. 2006; EASTERBROOK, Frank. Ways of criticizing the court. Harvard Law Review, Cambridge, vol. 95 , n. 4, p. 802-832, feb. 1982; ARROW, Kenneth Joseph. Social choice and individual values. New York: Jon Wiley \& Sons, 1963; ARROW, Kenneth Joseph. A difficulty in the concept of social welfare. Journal of Political Economy, Chicago, vol. 58, n. 4, p. 328-346, 1950; MORREAU, Michael. Arrow's Theorem. Stanford Encyclopedia of Philosophy, 2014. Disponível em: <https://philpapers.org/rec/MORAT>; SPECTOR, Hector. Constitutional choice, deliberation and Arrovian dictatorship. Palestra proferida no II Congresso Internacional de Direito Constitucional e Filosofia Política, na Escola Superior Dom Helder Câmara, na cidade Belo Horizonte, 26 nov. 2015.
} 


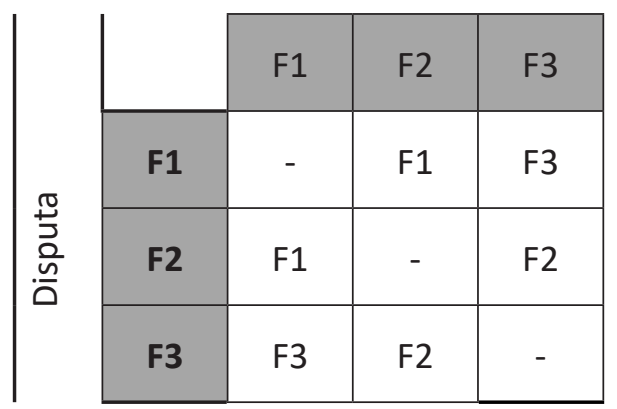

O teorema de Arrow ${ }^{26}$, por sua vez, prova que é impossível que um mecanismo de agregação de preferências respeite simultaneamente cinco condições ${ }^{27}$. São elas ${ }^{28}$ :

1 - Domínio Irrestrito: dentre as opções disponíveis, os participantes da votação podem ter qualquer ordem de preferência, de maneira que é necessário que o sistema de votação não restrinja nenhuma ordem ou combinação de ordens possível ${ }^{29}$.

$2 a$ - Ordenação social: o resultado da votação tem que ser um ranking das alternativas, da melhor para a pior, que pode ou não conter empates. Não pode haver a circularidade das alternativas, como acontece no caso do paradoxo da votação (como pode ser intuído facilmente, essa é a condição que não é cumprida no caso do sistema deliberativo do STF $)^{30}$.

${ }^{26}$ ARROW, Kenneth Joseph. Social choice and individual values. New York: Jon Wiley \& Sons, 1963; ARROW, Kenneth Joseph. A difficulty in the concept of social welfare. Journal of Political Economy, Chicago, vol. 58, n. 4, p. 328-346, 1950.

${ }^{27}$ MEYERSON, Michael. The irrational Supreme Court. Nebraska Law Review, Nebraska, vol. 84, n. 3, p. 895-961, jul./sept. 2006; EASTERBROOK, Frank. Ways of criticizing the court. Harvard Law Review, Cambridge, vol. 95 , n. 4, p. 802-832, feb. 1982; MORREAU, Michael. Arrow's Theorem. Stanford Encyclopedia of Philosophy, 2014. Disponível em: <https://philpapers.org/rec/MORAT>; SPECTOR, Hector. Constitutional choice, deliberation and Arrovian dictatorship. Palestra proferida no II Congresso Internacional de Direito Constitucional e Filosofia Política, na Escola Superior Dom Helder Câmara, na cidade Belo Horizonte, 26 nov. 2015.

${ }^{28}$ Para fins dessa exposição, nos baseamos majoritariamente em MORREAU, Michael. Arrow's Theorem. Stanford Encyclopedia of Philosophy, 2014. Disponível em: <https://philpapers.org/rec/MORAT> que oferece discussões detalhadas sobre cada uma das condições do teorema de Arrow.

${ }^{29}$ Easterbrook caracteriza essa condição como "range": "The system must allow every ranking of admissible choices, and there must be at least three admissible choices with no other institution to declare choices or rankings out of bounds at the start" (EASTERBROOK, Frank. Ways of criticizing the court. Harvard Law Review, Cambridge, vol. 95, n. 4, p. 802-832, feb. 1982, p. 823). Essa definição, embora pareça, a primeira vista, muito forte, é defendida por Easterbrook como consistente com o modo de deliberação do judiciário. Ele diz que excluir certas opções através de regras, por exemplo, não viola a condição desde que restem ao menos três opções (EASTERBROOK, Frank. Ways of criticizing the court. Harvard Law Review, Cambridge, vol. 95, n. 4, p. 802-832, feb. 1982, p. 825).

${ }^{30}$ Uma outra formulação dessa condição é dada em termos de "path independence", que Moreau (MORREAU, Michael. Arrow's Theorem. Stanford Encyclopedia of Philosophy, 2014. Disponível em: <https://philpapers. org/rec/MORAT>) atribui a Charles Plott. Essa formulação está incorporada na apresentação que Easterbrook 
$3 a$ - Weak Pareto: se todos os membros do grupo de indivíduos preferirem a opção $X \grave{a}$ opção $Y$, então o grupo prefere $X a Y$.

4a-Não ditadura: alguém é um ditador, no sentido de Arrow, se toda vez que ele preferir uma alternativa à outra, o grupo como um todo também preferir aquela alternativa. As preferências dos outros indivíduos só fazem diferença quando o ditador é indiferente entre aquelas opções.

5a-Independência das alternativas irrelevantes: "[o método de votação] tem que tomar cada par de alternativas de forma separada, sem prestar atenção às preferências para alternativas que não elas" ${ }^{\prime \prime}$. Essa é a condição menos intuitiva e mais controversa do teorema de Arrow. Easterbrook a define da seguinte forma: "A escolha entre as opções $A$ e B depende exclusivamente da comparação entre essas duas" ${ }^{\prime 32}$.

O teorema da impossibilidade de Arrow ${ }^{33}$, na formulação de Morreau, diz o seguinte: "Imagine que existem mais de duas alternativas. Então nenhuma função de bem-estar social $f$ satisfaz as condições $1 a, 2 a, 3 a, 4 a$ e $5 a^{\prime \prime 34}$. O que isso quer dizer? Que nenhum método para agregar as preferências de duas pessoas ou mais ("função de bem-estar social $f^{\prime}$ ) entre pelo menos três alternativas respeita, simultaneamente, as 5 condições elencadas acima.

O paradoxo da votação é uma instância de votação que está sob o escopo do teorema da impossibilidade de Arrow. Ele desrespeita a condição 2a, como vimos, o que significa que o sistema pode resultar em preferências cíclicas.

faz das condições do teorema de Arrow ("Transitivity is the condition of logical ordering plus path independence"
EASTERBROOK, Frank. Ways of criticizing the court. Harvard Law Review, Cambridge, vol. 95, n. 4, p. 802-832,
feb. 1982, p. 830) e é atacada por Kornhauser e Sager ("we explicitly consider situations in which the the appli-
cation of criteria for coherence are path dependent" KORNHAUSER, Lewis A.; SAGER, Lawrence G. Unpacking the
court. The Yale Law Journal, Danvers, vol. 96, n. 1, p. 82-117. 1986, p. 102). Porém, mostra que embora seja
possível formular a condição de ordenação social em termos mais fracos, isso pode não ser desejável. Os moti-
vos dessa indesejabilidade fogem do escopo do presente artigo. ${ }^{31}$ MORREAU, Michael. Arrow's Theorem. Stanford Encyclopedia of Philosophy, 2014. Disponível em: <https:// philpapers.org/rec/MORAT>.

${ }^{32}$ EASTERBROOK, Frank. Ways of criticizing the court. Harvard Law Review, Cambridge, vol. 95, n. 4, p. 802832, feb. 1982, p. 823.

${ }^{33}$ Curiosamente, Arrow o batizou de teorema da possibilidade (ARROW, Kenneth Joseph. A difficulty in the concept of social welfare. Journal of Political Economy, Chicago, vol. 58, n. 4, p. 328-346. 1950, p. 339; ARROW, Kenneth Joseph. Social choice and individual values. New York: Jon Wiley \& Sons, 1963, p. 46). Atualmente, porém, é comum referir-se ao teorema como teorema da impossibilidade de Arrow. Vide MORREAU, Michael. Arrow's Theorem. Stanford Encyclopedia of Philosophy, 2014. Disponível em: <https://philpapers.org/rec/ MORAT>.; MEYERSON, Michael. The irrational Supreme Court. Nebraska Law Review, Nebraska, vol. 84, n. 3, p. 895-961, jul./sept. 2006; EASTERBROOK, Frank. Ways of criticizing the court. Harvard Law Review, Cambridge, vol. 95, n. 4, p. 802-832, feb. 1982; KORNHAUSER, Lewis A.; SAGER, Lawrence G. Unpacking the court. The Yale Law Journal, Danvers, vol. 96, n. 1, p. 82-117. 1986.

${ }^{34}$ MORREAU, Michael. Arrow's Theorem. Stanford Encyclopedia of Philosophy, 2014. Disponível em: <https:// philpapers.org/rec/MORAT>. Ligeiramente modificado do original (Morreau), que diz: "Suppose there are more than two alternatives. Then no social welfare function $f$ satisfies $U, S O, W P, D$, and I". 
O que isso significa para o direito? Isso vai depender de algumas coisas, mas a primeira e mais importante delas é perguntar: será que as condições acima são, todas, concomitantemente aplicáveis à deliberação dos tribunais? É o que pretende-se investigar na próxima seção.

\section{ARROW E OS TRIBUNAIS}

De pronto, podemos perceber que algumas das condições de Arrow podem ser aplicadas a todos os casos de julgamentos colegiados: sempre teremos duas ou mais pessoas julgando três ou mais alternativas, ao menos no caso dos fundamentos possíveis da decisão; essas alternativas sempre poderão ser classificadas em qualquer ordem de preferência pelos membros individuais do tribunal; se todos os juízes do tribunal concordarem que o fundamento 1 é melhor do que o fundamento 2, o tribunal terá decidido com base no fundamento 1. Assim, as condições 1a e 3a são obviamente descritivamente verdadeiras e parecem ser normativamente desejáveis ${ }^{35}$.

A condição $2 a$, de maneira similar, também se demonstra desejável. Afinal, se imaginarmos que o problema da dispersão de fundamentos é algo a ser solucionado, devemos nos preocupar em satisfazer essa condição (2a), garantindo que a deliberação do tribunal sempre seja capaz de fornecer algum fundamento para as suas decisões ${ }^{36}$.

A situação se complica um pouco quanto às condições 4a e 5a. À primeira vista, ambas parecem intuitivamente aceitáveis. Seria forçoso imaginar que os tribunais de fato funcionem como entidades ditatoriais, em que o voto de um de seus membros sempre determina o resultado do grupo ${ }^{37}$. Da mesma forma, parece que as alternativas independentes são irrelevantes: se o tribunal está avaliando os fundamentos 1 e 2, esse julgamento não tem nada a ver com o fundamento 3; o tribunal está pura e simplesmente avaliando um argumento com relação ao outro. No entanto, a situação não é tão simples assim.

Um arranjo institucional em que todos os ministros sempre acompanhassem o relator seria um sistema de votação que desrespeitaria, pelo menos, a condição 4a:

\footnotetext{
${ }^{35}$ Para estabelecer a desejabilidade ou indesejabilidade normativa de cada uma das condições, seria necessário um esforço muito maior. Queremos apenas mostrar que, intuitivamente, não parece ser o caso de que qualquer uma das condições seja normativamente dispensável.

${ }^{36}$ KORNHAUSER, Lewis A.; SAGER, Lawrence G. Unpacking the court. The Yale Law Journal, Danvers, vol. 96, n. 1, p. 82-117. 1986, como vimos, não concordam com a aplicabilidade da condição, mas cremos que a formulação acima é suficientemente aceitável para os fins do argumento que pretendemos desenvolver. A objeção mereceria um exame mais detalhado que foge ao escopo do presente. Portanto, preferimos delegar ao leitor a tarefa de avaliar a pertinência da objeção dos autores.

${ }^{37}$ Uma análise sobre a regularidade do uso de "nos termos do relator" em julgados do STF, no entanto, sugere que a Corte vem agindo de maneira, conforme descreve Arrow, ditatorial. Para uma lição mais aprofundada sobre o assunto, ver ALMEIDA, Danilo dos Santos; BOGOSSIAN, André Martins. "Nos termos do voto do relator": considerações acerca da fundamentação coletiva nos acórdãos do STF. Revista Estudos Institucionais, vol. 2, n.1, p. 264-297, jan./jun. 2016.
} 
o sistema seria ditatorial, seguindo o termo técnico de Arrow, já que um determinado membro do tribunal (se considerarmos "relator" como membro, e não cada um dos indivíduos que ocupasse essa função em julgamentos diferentes) sempre determinaria o resultado da preferência do grupo. Essa condição, porém, pode ser desrespeitada de maneiras mais sutis. Imaginemos uma turma com três desembargadores. O primeiro desembargador (1) vota sempre de maneira consistente conforme sua ordenação de preferências pessoais P. O segundo desembargador (2) também vota sempre de maneira consistente com a sua ordenação de preferências pessoais $P^{\prime}$, mas $P^{\prime}$ é exatamente a ordem inversa a P. Assim, se P ordena as opções na ordem A, B e C, $P^{\prime}$ ordena as opções na ordem C, B e A. O terceiro desembargador (3) é extremamente preguiçoso e não tem muita preocupação nem com a consistência de suas opiniões pessoais, nem com o estudo cuidadoso dos casos sob análise. Ele se limita a seguir, em cada caso, o voto de um dos outros dois desembargadores. Como as preferências dos desembargadores 1 e 2 nunca mudam, a opinião do grupo é sempre determinada exclusivamente pela opinião do desembargador 3, ainda que ele não pareça contar como um ditador no significado que essa palavra tem na linguagem ordinária. Isso faz com que o desembargador 3 seja um ditador, no sentido técnico do termo conforme empregado por Arrow ${ }^{38}$.

Embora possamos conviver com a existência do desembargador 3, ela não nos deve causar muito conforto. Não é razoável que o juiz menos cuidadoso e menos consistente decida aleatoriamente casos importantes, ainda que o faça seguindo o voto de um de seus colegas mais cuidadosos e consistentes. Assim, parece difícil negar a aplicabilidade da condição 4a à deliberação jurídica, ou ao menos àquela realizada nos chamados casos difíceis do Direito, como, por exemplo, aqueles considerados como moralmente carregados. De fato, parte da literatura é enfática ao defender que as cortes não devem funcionar de maneira ditatorial. Virgílio Afonso da Silva afirma que: “Uma das precondições de uma deliberação justa [...] é a igualdade de juízes dentro de uma corte ${ }^{\prime \prime 39}$.

Existem, por outro lado, evidências no sentido de que o STF, na grande maioria dos casos, de fato assuma uma posição na qual se "atribui ao relator o papel central de prover fundamentação para a decisão coletiva"40. Se essa é uma visão descritivamente

\footnotetext{
${ }^{38} \mathrm{O}$ exemplo acima é uma variação do exemplo apresentado por MORREAU, Michael. Arrow's Theorem. Stanford Encyclopedia of Philosophy, 2014. Disponível em: <https://philpapers.org/rec/MORAT>. O exemplo de Morreau, por sua vez, é derivado de um documentário dirigido por Woody Allen.

${ }^{39}$ SILVA, Virgílio Afonso da. Deciding without deliberating. International Journal of Constitutional Law, vol. 11 , n. 3, p. 557-584, jul./sept. 2013, p. 571.

${ }^{40}$ ALMEIDA, Danilo dos Santos; BOGOSSIAN, André Martins. "Nos termos do voto do relator": considerações acerca da fundamentação coletiva nos acórdãos do STF. Revista Estudos Institucionais, vol. 2, n.1, p. 290, jan./jun. 2016.
} 
correta acerca do comportamento deliberativo do tribunal ${ }^{41}$, ele seria uma ditadura arroviana e chegaria a decisões fundamentadas através do desrespeito à condição 4a.

A rigor, embora a condição 5a seja desrespeitada em muitos arranjos de votação e pareça ser uma estratégia mais ou menos comum para garantir a transitividade de uma função de agregação de preferências, ela parece ser indispensável ao direito. Se tomarmos a descrição que Easterbrook faz da condição, veremos que: "[decisões judiciais] não deveriam ser influenciadas pelas crenças que um juiz tem sobre a conveniência da provisão legal; menos ainda por uma crença muito forte de um juiz de que o sistema de negligência é uma maneira pervertida de lidar com casos de colisão automobilística ou que reclamantes ruivos (ou negros) devem perder"42. Se essa é uma descrição adequada dos requisitos de 5 a, parece claro que juristas das mais diversas escolas de pensamento (formalistas e particularistas, por exemplo ${ }^{43}$ ) concordariam que ela se aplica ao caso das decisões jurídicas.

Se todas as considerações supra são verdadeiras, as soluções consideradas por Brando e Leite ${ }^{44}$ não são capazes de eliminar o problema. Afinal, elas não agem sobre nenhuma de suas causas ( $1 \mathrm{a}-5 \mathrm{a}$ ). Naturalmente, podemos imaginar que elas diminuam as hipóteses nas quais não teremos um vencedor de Condorcet. É possível que o mero fato de trazer a atenção do público e dos juízes para os fundamentos das decisões de um tribunal, em especial quando estamos falando do STF em matéria de controle concentrado de constitucionalidade, seja capaz de causar algum efeito positivo quanto à redução da quantidade de casos nos quais ficaremos sem uma ratio decidendi. Conforme veremos, a intuição dos autores de que a relativa indeterminação do texto constitucional e a causa de pedir aberta contribuem para o problema também parecem estar corretas.

A proposta principal de Brando e Leite ${ }^{45}$, porém, é interessante pelas peculiaridades que sua adoção enseja e pela curiosa realidade que ela revela. Trata-se do fenômeno do "paradoxo doutrinário"46.

\footnotetext{
${ }^{41}$ Os dados empíricos apresentados pelos autores discordam de algumas outras pesquisas empíricas que possuíam acesso a dados mais profundos a respeito dos votos de ministros individuais. Nesse sentido: ROSEVEAR, Evan; HARTMANN, Ivar Alberto; ARGUELHES, Diego Werneck. Disagreement on the Brazilian supreme court: an exploratory analysis. Disponível em: <http://papers.ssrn.com/sol3/papers.cfm?abstract_id=2629329>. Acesso em: 25 jan. 2018.

${ }^{42}$ EASTERBROOK, Frank. Ways of criticizing the court. Harvard Law Review, Cambridge, vol. 95, n. 4, p. 802832, feb. 1982, p. 825. Tradução dos autores.

${ }^{43}$ Vide SCHAUER, Frederick, Playing By The Rules: A Philosophical Examination of Rule-Based Decision-Making in Law and in Life. Oxford: Oxford University Press, 1991.

${ }^{44}$ BRANDO, Marcelo Santini; LEITE, Fábio Carvalho. Dispersão de fundamentos no Supremo Tribunal Federal. Revista Direito, Estado e Sociedade, Rio de Janeiro, n. 48, p. 139-166, jan./jun. 2016.

${ }^{45}$ BRANDO, Marcelo Santini; LEITE, Fábio Carvalho. Dispersão de fundamentos no Supremo Tribunal Federal. Revista Direito, Estado e Sociedade, Rio de Janeiro, n. 48, p. 139-166, jan./jun. 2016.

${ }^{46}$ KORNHAUSER, Lewis A.; SAGER, Lawrence G. Unpacking the court. The Yale Law Journal, Danvers, vol. 96, n. 1, p. 82-117. 1986; MEYERSON, Michael. The irrational Supreme Court. Nebraska Law Review, Nebraska, vol. 84, n. 3, p. 895-961, jul./sept. 2006.
} 


\section{PARADOXO DOUTRINÁRIO}

O artigo publicado por Kornhauser e Sager em 1986, intitulado Unpacking the court ${ }^{47}$, demonstrou, pela primeira vez, a existência do fenômeno que os autores batizaram de "paradoxo doutrinário". O fenômeno que Kornhauser e Sager observaram é tão simples quanto o paradoxo da votação e tão interessante quanto ele com relação às suas consequências normativas para a teoria da adjudicação. Para usar o exemplo dos autores, imagine que um grupo de três juízes tenha que decidir sobre a inconstitucionalidade de uma determinada lei L. Os argumentos levantados pelas partes e amici ouvidos no processo se dividem em três questões diferentes: $Q_{1}-L$ é formalmente inconstitucional; $Q_{2}-L$ desrespeita o princípio fundamental $X$ e $Q_{3}-L$ desrespeita o princípio fundamental Y.

Apesar da presunção de constitucionalidade das leis, é fácil perceber que $L$ só não será declarada inconstitucional quando: $\left(Q_{1}\right)$ ela não for formalmente inconstitucional; $\left(Q_{2}\right)$, não desrespeitar o princípio fundamental $X ;$ e $\left(Q_{3}\right)$ não desrespeitar o direito fundamental $Y$. Se todos os juízes pensam que $L$ é formalmente inconstitucional, por exemplo, não importa se acreditam que ela não desrespeita o fundamento $X$ ou o fundamento $Y$, ela é inconstitucional por $Q_{1}$. Isso vale para todas as combinações possíveis: se o tribunal resolver que $L$ fere qualquer uma das três questões apresentadas $\left(Q_{1}, Q_{2} \text { e } Q_{3}\right)^{48}$, $L$ deve ser declarada inconstitucional. De forma contrária, $L$ não deve ser declarada constitucional se, e somente se, o tribunal concluir que ela não fere nenhuma das questões apresentadas.

Imaginemos que a votação do tribunal se dê segundo o seguinte padrão:

\begin{tabular}{|c|c|c|c|c|}
\cline { 2 - 5 } & L Fere $Q_{1}$ ? & L Fere $Q_{2}$ ? & L Fere $Q_{3}$ ? & Inconstitucional? \\
\hline Juiz 1 & Sim & Não & Não & Sim \\
\hline Juiz 2 & Não & Sim & Não & Sim \\
\hline Juiz 3 & Não & Não & Sim & Sim \\
\hline
\end{tabular}

${ }^{47}$ KORNHAUSER, Lewis A.; SAGER, Lawrence G. Unpacking the court. The Yale Law Journal, Danvers, vol. 96, n. 1, p. 82-117. 1986.

${ }^{48}$ É bem verdade que, como afirmam BRANDO, Marcelo Santini; LEITE, Fábio Carvalho. Dispersão de fundamentos no Supremo Tribunal Federal. Revista Direito, Estado e Sociedade, Rio de Janeiro, n. 48, p. 139-166, jan./ jun. 2016, a situação seja ainda mais complicada no direito brasileiro: afinal, a interpretação do tribunal de que as ações do controle concentrado possuem causa de pedir aberta - ou seja, que o tribunal pode decidir com base em qualquer fundamento, não estando restrito àqueles apresentados pelas parte e pelos amici - torna o número de questões potencialmente indeterminado. 
Como vemos, nesse caso, o tribunal decidiu, sobre cada uma das questões $\left(Q_{1}{ }^{-}\right.$ $Q_{3}$ ) que $L$ não feria nenhuma delas. Em cada uma dessas questões, o tribunal, por uma maioria de 2 a 1 decidiu que a lei não feria a questão. Seria intuitivo, portanto, imaginar que $L$ é constitucional. Porém, quanto ao resultado do julgamento, o tribunal foi unânime: todos os juízes consideraram $L$ inconstitucional.

Kornhauser e Sager ${ }^{49}$ notaram que o resultado desse esquema de votação é insatisfatório ou irracional ${ }^{50}$; afinal, imaginamos que $Q_{1}-Q_{3}$ sejam as únicas questões relevantes para respondermos à pergunta sobre a constitucionalidade de $L$, mas, mesmo que $L$ seja considerada constitucional caso sejam contados os votos por questão, L é considerada inconstitucional por unanimidade, quando levado em consideração a decisão final de cada ministro.

Nesse caso, a proposta de Brando e Leite ${ }^{51}$ muda o resultado do julgamento: se usarmos a regra de votação por maioria simples, o resultado será que $L$ é inconstitucional, mas se usarmos a regra de votação vinculada aos fundamentos, o resultado será que $L$ não é constitucional. Será que essa mudança resolve o paradoxo doutrinário? O resultado obtido através da aplicação dessa regra não é tão estranho quanto o resultado obtido através da regra de votação por maioria simples? Afinal, parece muito estranho aceitar uma decisão colegiada cujo resultado não era desejado por nenhum dos participantes ${ }^{52}$.

Existe uma conexão entre o teorema da impossibilidade de Arrow e o paradoxo doutrinário, explorada por List e Pettit para propor um novo conjunto de condições que expressam um teorema de impossibilidade próprio $^{53}$. Assim como nenhum mecanismo para agregação de preferências pode respeitar, simultaneamente, as cinco condições enumeradas por Arrow, nenhum mecanismo para agregação de julgamentos pode

${ }^{49}$ KORNHAUSER, Lewis A.; SAGER, Lawrence G. Unpacking the court. The Yale Law Journal, Danvers, vol. 96, n. 1, p. 82-117. 1986.

${ }^{50}$ MEYERSON, Michael. The irrational Supreme Court. Nebraska Law Review, Nebraska, vol. 84, n. 3, p. 895-961, jul./sept. 2006.

${ }^{51}$ BRANDO, Marcelo Santini; LEITE, Fábio Carvalho. Dispersão de fundamentos no Supremo Tribunal Federal. Revista Direito, Estado e Sociedade, Rio de Janeiro, n. 48, p. 139-166, jan./jun. 2016.

${ }^{52}$ Essa estranheza é proveniente do fato de enxergamos grupos como entes capazes de tomar decisões fundamentadas. Ou seja, entendemos que grupos assumem a feição de agentes quando pessoas agem em 'atividades cooperativas compartilhadas', nas quais há ao menos um objetivo em comum, conhecido por todos e de forma que eles o façam ou busquem juntos e coordenem suas funções - seus planos e subplanos de ação, incluindo ajudar o outro na sua função, se necessário -, que são interdependentes. Isso demonstra que a nossa leitura sobre agenciamento também atribui intencionalidade aos atos executados por grupo. A questão é como enxergar essa intencionalidade. Se for lida como a soma das intenções dos agentes que compõem o grupo, surge a estranheza relatada. Afinal, como seria possível atingir uma decisão que nenhum dos componentes do grupo desejaria como agente individual ou para o grupo enquanto agente coletivo? Para uma discussão mais aprofundada sobre o assunto, ver: TUOMELA, Raimo. Group reasons. Philosophical Issues, vol. 22, issue 1, p. 402-418, oct. 2012.

${ }^{53}$ LIST, Christian e PETTIT, Philip. Aggregating sets of judegements: two impossibility results compared. Synthese. Vol.140, Issue 1, 2004, pp. 207-235. 
respeitar simultaneamente as condições enumeradas por List e Pettit ${ }^{54}$. A diferença entre os dois casos é simples: enquanto o teorema de Arrow se aplica à agregação de preferências, que podem ser ordenadas entre si, o teorema da impossibilidade de List e Pettit ${ }^{55}$ se aplica à agregação de julgamentos. Julgamentos, segundo List e Pettit, são "atos de concordância ou discordância, asserção ou negação, e diferem de crenças em não permitir graus de confiança" ${ }^{\prime \prime 6}$. As complicações surgem quando um grupo precisa agregar um conjunto de julgamentos sobre questões "que são tratadas como interconectadas, ao invés de independentes" ${ }^{157}$.

Os dois problemas - agregação de preferências e agregação de julgamentos são similares e, em parte por isso, os teoremas de Arrow, por um lado, e List e Pettit, por outro, também possuem muitas semelhanças ${ }^{58}$. Eles diferem principalmente com relação às suas definições/hipóteses de incidência. Enquanto Arrow se aplica à agregação de preferências, o teorema da impossibilidade de List e Pettit se aplica à agregação de julgamentos; enquanto Arrow se aplica a casos em que três ou mais pessoas ordenam suas preferências entre três ou mais opções, o teorema de List e Pettit se aplica a casos onde duas ou mais pessoas têm que realizar julgamentos sobre duas ou mais questões que não são independentes entre si.

Para colocar a questão em termos mais abstratos, basta pensarmos que a conclusão " $L$ é constitucional" acontece se e somente se a resposta a $Q_{1}, Q_{2}$ e $Q_{3}$ forem simultaneamente negativas, ou seja, se nenhuma das inconstitucionalidades alegadas de fato ocorrer ${ }^{59}$. No quadro supra, o tribunal como um todo - se adotarmos a regra de votação por maioria vinculada aos fundamentos - decidiu que $Q_{1}, Q_{2}$ e $Q_{3}$ devem ser respondidos negativamente. Logo, de acordo com a lógica que acabamos de estabelecer, chegaremos à conclusão de que $L$ é constitucional. O paradoxo surge quando notamos que os três juízes creem que L é inconstitucional.

Como no caso da agregação de preferências, também na agregação de julgamentos é impossível satisfazer algumas condições que nos parecem razoáveis. São elas:

\footnotetext{
${ }^{54}$ LIST, Christian; PETTIT, Philip. Aggregating sets of judgement: an impossibility result. Economics and Philosophy, Cambridge, vol. 18, n. 1, p. 89-110, apr. 2002.

${ }^{55}$ LIST, Christian; PETTIT, Philip. Aggregating sets of judgement: an impossibility result. Economics and Philosophy, Cambridge, vol. 18, n. 1, p. 89-110, apr. 2002.

${ }^{56}$ LIST, Christian; PETTIT, Philip. Aggregating sets of judgement: an impossibility result. Economics and Philosophy, Cambridge, vol. 18, n. 1, p. 207-235, apr. 2002, p. 90. Tradução dos autores.

${ }^{57}$ LIST, Christian; PETTIT, Philip. Aggregating sets of judgement: an impossibility result. Economics and Philosophy, Cambridge, vol. 18, n. 1, p. 207-235, apr. 2002, p. 90. Tradução dos autores.

${ }^{58}$ Para uma comparação, ver LIST, Christian; PETTIT, Philip. Aggregating sets of judgement: an impossibility result. Economics and Philosophy, Cambridge, vol. 18, n. 1, p. 207-235, apr. 2002.

${ }^{59}$ É nesse sentido que Q1, Q2 e Q3 não são independentes: as conclusões podem ser definidas como uma função do julgamento dessas três questões. Se Q1, Q2 ou Q3 forem verdadeiros, L é inconstitucional; se Q1, Q2 e Q3 forem falsos, L é constitucional.
} 
16 - Domínio Universal: A função deve aceitar todas as opções possíveis de julgamentos individuais que sejam consistentes (não existe contradição interna; um julgador não decide, simultaneamente, que $P$ e que não $P$ ) e completas (cada julgador responde a todas as questões);

$2 b$ - Racionalidade Coletiva: Para quaisquer julgamentos individuais dos julgadores, a função agregadora deve gerar um resultado consistente e completo;

3 - Sistematicidade: "(i) o julgamento coletivo sobre cada proposição em X [o conjunto de proposições sob julgamento] depende exclusivamente dos julgamentos individuais sobre aquela proposição e não dos julgamentos individuais sobre outras proposições (a parte da independência), e (ii) o critério para determinar o julgamento coletivo sobre cada proposição deve ser o mesmo sobre todas as proposições em X (a parte da neutralidade)"

$4 b$ - Anonimato: $O$ voto de cada um dos julgadores é considerado igual. O julgamento de nenhum dos julgadores pode ter um peso maior. ${ }^{61}$

Imediatamente, podemos observar que, embora as condições do teorema de Arrow não sejam estritamente idênticas nem equivalentes às do teorema de List e Pettit, ambas são muito similares ${ }^{62}$. Domínio universal (1b) e domínio irrestrito (1a) são condições praticamente idênticas. Sistematicidade (3b) guarda fortes semelhanças com a independência das alternativas irrelevantes (3a) e, finalmente, anonimato (4b) parece equivalente à ideia de não-ditadura (4a). A grande diferença, que parece ser relevante, está na identificação dos problemas. Arrow, em parte motivado pelo paradoxo da votação, postula o requisito $2 a$, que tem como objetivo justamente garantir que não teremos resultados cíclicos na agregação de preferências. List e Pettit, motivados pelo paradoxo doutrinário de Kornhauser e Sager ${ }^{63}$, postulam $2 b$, a exigência de que a função sempre gere resultados "racionais". Assim sendo, e especialmente por causa das origens jurídicas do problema, acreditamos não ser necessário repetir a argumentação sobre a aplicabilidade de cada uma das condições ao problema específico da agregação de preferências jurídicas.

Na realidade, List e Pettit provaram que é possível formular o paradoxo da votação de maneira que ele esteja sujeito ao teorema da impossibilidade que postularam

\footnotetext{
${ }^{60}$ Para uma comparação, ver LIST, Christian. The theory of judgement aggregation: an introductory review. Synthese, Vol. 187, Issue 1, 2012, pp. 197-207.

${ }^{61}$ As condições foram extraídas de LIST, Christian. The theory of judgement aggregation: an introductory review. Synthese, Vol. 187, Issue 1, 2012, pp. 186-187.

${ }^{62}$ LIST, Christian; PETTIT, Philip. Aggregating sets of judgement: an impossibility result. Economics and Philosophy, Cambridge, vol. 18, n. 1, p. 207-235, apr. 2002, faz uma comparação entre essas condições, chegando à mesma conclusão.

${ }^{63}$ KORNHAUSER, Lewis A.; SAGER, Lawrence G. Unpacking the court. The Yale Law Journal, Danvers, vol. 96, n. 1, p. 82-117. 1986.
} 
em $2002^{64}$. Basta que consideremos a ordem de preferência como um julgamento sobre a relação estrita entre as opções. Assim, ao invés de cada julgador ordenar suas preferências com relação às opções $A, B$ e $C$, cada um emitirá seu julgamento com relação a proposições relacionais do tipo: "A é preferível a B"65.

Ainda que esse seja o caso, parece relevante a opção por expor os dois problemas de maneira separada. Eles evidenciam duas dificuldades diferentes, ainda que essas dificuldades tenham a mesma causa. Por um lado, há a dificuldade, foco dos artigos de Brando e Leite ${ }^{66}$ e Vojvodic, Machado e Cardoso ${ }^{67}$ em definir a ratio decidendi de um julgado. Afinal, juízes têm muitas opções de fundamentação e a falta de mecanismos explícitos de decisão majoritária no STF, em particular, e em tribunais, em geral, é um agravante para o problema, ainda que não possa ser considerada sua causa exclusiva. Por outro lado, agregar preferências é significativamente diferente de agregar julgamentos e é possível argumentar que juízes prototipicamente agregam julgamentos, não preferências ${ }^{68}$.

Por outro lado, não é difícil perceber que, ao menos no caso do direito, autores como Easterbrook $^{69}$, Meyerson ${ }^{70}$ e Kornhauser e Sager ${ }^{71}$ estão falando sobre a mesma coisa. Afinal, poucos juristas diriam que a resposta a questões como $Q_{1}, Q_{2}$ e $Q_{3}$ contam como a decisão. Acreditamos que a maioria dos juristas diria que $Q_{1}, Q_{2}$ ou $Q_{3}$ seriam a razão de decidir (ratio decidendi): a lei $L$ é inconstitucional (decisão propriamente dita ou dispositivo da decisão) porque ela fere $\mathrm{Q}_{1}, \mathrm{Q}_{2}$ ou $\mathrm{Q}_{3}{ }^{72}$.

${ }^{64}$ LIST, Christian; PETTIT, Philip. Aggregating sets of judgement: an impossibility result. Economics and Philo-
sophy, Cambridge, vol. 18, n. 1, p. 207-235, apr. 2002.
${ }^{65}$ Ou "A é indiferente com relação a B", para a ideia de ordenação fraca, com empates.
${ }^{66}$ BRANDO, Marcelo Santini; LEITE, Fábio Carvalho. Dispersão de fundamentos no Supremo Tribunal Federal. Revista Direito, Estado e Sociedade, Rio de Janeiro, n. 48, p. 139-166, jan./jun. 2016.

${ }^{67}$ VOJVODIC, Adriana de Moraes; MACHADO, Ana Mara França; CARDOSO, Evorah Lusci Costa. Escrevendo um romance, primeiro capítulo: precedentes e processo decisório no STF. Revista Direito GV, São Paulo, vol. 5, n. 1, p. 21-44, jan./jun. 2009.

${ }^{68}$ MEYERSON, Michael. The irrational Supreme Court. Nebraska Law Review, Nebraska, vol. 84, n. 3, p. 895-961, jul./sept. 2006; e KORNHAUSER, Lewis A.; SAGER, Lawrence G. Unpacking the court. The Yale Law Journal, Danvers, vol. 96, n. 1, p. 82-117. 1986.

${ }^{69}$ EASTERBROOK, Frank. Ways of criticizing the court. Harvard Law Review, Cambridge, vol. 95, n. 4, p. 802832, feb. 1982.

${ }^{70}$ MEYERSON, Michael. The irrational Supreme Court. Nebraska Law Review, Nebraska, vol. 84, n. 3, p. 895-961, jul./sept. 2006.

${ }^{71}$ KORNHAUSER, Lewis A.; SAGER, Lawrence G. Unpacking the court. The Yale Law Journal, Danvers, vol. 96, n. 1, p. 82-117. 1986.

${ }^{72}$ Note-se que embora essa possa ser a forma mais acurada de descrever nossa percepção de mente em grupos, ela pode continuar não sendo a mais desejável do ponto de vista normativo. Pode ser, inclusive, que mesmo do ponto de vista descritivo essa seja uma visão incompleta. Afinal, os próprios membros do grupo-agente possivelmente discordariam sobre essa leitura acerca da fundamentação da decisão tomada por eles. Tendo em vista que grupos "agem através de seus membros, mais especificamente, através da aceitação conjunta dos membros de razões para a ação do grupo Isso exige que os membros expressem essa aceitação, subjetivamente, pensando e agindo como partes do grupo (em oposição a pensar e agir em satisfação a seus interesses 
Será que existe tanta diferença entre perguntar para cada um dos julgadores sobre a sua preferência entre as opções de fundamentação $Q_{1}, Q_{2}$ e $Q_{3}$ e pedir para que cada um deles emita um julgamento sobre $\mathrm{Q}_{1}, \mathrm{Q}_{2}$ e $\mathrm{Q}_{3}$ ? Acreditamos que, do ponto de vista abstrato, possamos classificar os dois problemas como problemas sobre a fundamentação de uma decisão. E a lição importante da literatura sobre teoria da escolha social é clara: formulemos a pergunta da maneira como quisermos formular, o problema existe e provavelmente continuará existindo, a não ser que resolvamos abrir mão de algumas coisas que nos parecem importantes: 1a-5a no caso da agregação de preferências e $1 b-4 b$ no caso da agregação de julgamentos. Será que isso é possível? Se sim, qual das condições deveríamos desrespeitar? List, em sua revisão sobre a literatura acerca da agregação de julgamentos ${ }^{73}$ nos mostra que os resultados não são muito promissores.

\section{CONCLUSÃO}

Sempre existe a possibilidade de que: 1) seja impossível identificar o fundamento preferido pela maioria dos ministros (ou seja, alguns julgamentos serão instâncias do paradoxo da votação) ou 2) o resultado seja irracional, com resultados diferentes resultantes da contagem dos votos por questão/fundamento ou pelo resultado (ou seja, alguns julgamentos serão instâncias do paradoxo doutrinário).

À luz disso, será que vale a pena mudar o sistema deliberativo do STF para que se adote a regra de votação vinculada aos fundamentos? Essa questão, a nosso ver, depende da seguinte consideração: temos bons motivos para acreditar que a adoção de tal regra reduzirá o número de instâncias onde (1) ou (2) ocorrem?

Intuitivamente, diríamos que sim: forçar os ministros a debater explicitamente sobre os fundamentos uns dos outros deve ser suficiente para aumentar o número de casos nos quais se forma maioria sobre o fundamento de uma determinada decisão. No arranjo atual, em que os ministros, na maior parte das vezes, leem seus votos em sequência e debatem ${ }^{74}$ majoritariamente a respeito da solução a ser dada em um caso

pessoais) e, objetivamente, em concordância com as regras, práticas e valores constitutivos do grupo" (ALMEIDA, Danilo dos Santos; BOGOSSIAN, André Martins. "Nos termos do voto do relator": considerações acerca da fundamentação coletiva nos acórdãos do STF. Revista Estudos Institucionais, vol. 2, n.1, p. 264-297, jan./jun. 2016, p. 275). Se esse é o caso, é perfeitamente possível que uma decisão coletiva expresse algo que não é o desejo individual de nenhum dos membros do grupo. Para maior profundidade sobre o tema, ver TUOMELA, Raimo. Group reasons. Philosophical Issues, vol. 22, issue 1, p. 402-418, oct. 2012. Para os fins do argumento tecido aqui, porém, é suficiente perceber que o STF, ao menos em um subconjunto dos casos, pode ser lido como agindo de maneira menos deliberativa e mais agregativa, se comportando mais como um conjunto de agentes individuais do que como um grupo-agente.

${ }^{73}$ LIST, Christian; PETTIT, Philip. Aggregating sets of judgement: an impossibility result. Economics and Philosophy, Cambridge, vol. 18, n. 1, p. 197-207, apr. 2002.

${ }^{74}$ Se é que debatem, ver SILVA, Virgílio Afonso da. Deciding without deliberating. International Journal of Constitutional Law, vol. 11, n. 3, p. 557-584, jul./sept. 2013. 
concreto, parece-nos mais provável que haja uma dispersão de fundamentos do que num cenário em que todos têm necessariamente que concordar especificamente com um dos fundamentos apresentados. ${ }^{75}$ Isso, naturalmente, convidará o voto estratégico por parte de alguns ministros. Talvez, em prol da obtenção de um resultado com o qual concordam, os ministros flexibilizarão suas convicções com relação aos fundamentos. Há evidências de que isso, inclusive, já tenha ocorrido em algumas votações importantes da Suprema Corte americana ${ }^{76}$.

Em qualquer caso, essa questão é parcialmente empírica (será que de fato a adoção de uma regra dessas reduziria os casos problemáticos?) e parcialmente conceitual (temos razões conceituais para acreditar que algum dos dois arranjos gera um número menor de combinações problemáticas?). Embora a literatura não tenha explorado o tema, essa parece ser uma linha promissora para pesquisa futura.

Com relação às outras duas sugestões de Brando e Leite ${ }^{77}$, porém, as respostas podem ser dadas com maior segurança. Krishnamoorthy e Raghavachari ${ }^{78}$ nos oferecem parte da resposta conceitual com relação ao potencial que a causa de pedir aberta e a relativa indeterminação do texto constitucional têm para agravar o problema. Os autores observam que, quando aumentamos o número de alternativas disponíveis para a ordenação de preferências entre um número constante de votantes, a probabilidade de que o resultado não seja cíclico diminui ${ }^{79}$. Por exemplo: se três votantes têm que ordenar suas preferências entre 3 opções, a probabilidade de que a votação fornecerá um resultado não cíclico é de $77 \%$. Se os mesmos três votantes têm que ordenar 10 opções, porém, a probabilidade de que o resultado será transitivo é de apenas $22 \%$. No limite, se os mesmos três votantes têm que escolher entre 101 opções, a probabilidade de que a votação fornecerá um resultado não cíclico é de 0,008\%. A conclusão, naturalmente, é

\footnotetext{
${ }^{75}$ Uma possibilidade (sugerida por um dos revisores anônimos) é que a culpa dos resultados paradoxais observados no presente artigo seja do sistema de votação seriatim adotado no caso brasileiro. Segundo essa interpretação, bastaria adotarmos um modelo per curiam, nos moldes, por exemplo, do que acontece na Suprema Corte dos EUA, para sanarmos os problemas identificados. Muito embora possa ser o caso que o modelo seriatim contribua para o problema, não é verdade que adotar um modelo per curiam seja suficiente para eliminar os resultados paradoxais. Afinal, boa parte da literatura que citamos identifica resultados desse tipo em julgados da Suprema Corte dos EUA. Vide MEYERSON, Michael. The irrational Supreme Court. Nebraska Law Review, vol. 84, n. 3, p. 895-961, 2006; KORNHAUSER, Lewis A.; SAGER, Lawrence G. Unpacking the court. The Yale Law Journal, vol. 96, n. 1, p. 82-117, 1986.

${ }^{76}$ MEYERSON, Michael. The irrational Supreme Court. Nebraska Law Review, Nebraska, vol. 84, n. 3, p. 895-961, jul./sept. 2006.

${ }_{77}$ BRANDO, Marcelo Santini; LEITE, Fábio Carvalho. Dispersão de fundamentos no Supremo Tribunal Federal. Revista Direito, Estado e Sociedade, Rio de Janeiro, n. 48, p. 139-166, jan./jun. 2016.

${ }^{78}$ KRISHNAMOORTHY, Mukkai S.; RAGHAVACHARI, Madabhushi. Condorcet winner probabilities - a statistical perspective. 2005. Disponível em: <http://arxiv.org/pdf/math/0511140.pdf>. Tabela 2.

${ }^{79}$ No mesmo sentido: NIEMI, Richard G.; WEISBERG, Herbert F. A mathematical solution for the probability of the paradox of voting. Behavioral Science, [s.I.], vol. 13, n. 4, p. 317-323. 1968.
} 
que, com $n$ opções, todos os resultados serão cíclicos ${ }^{80}$. Na realidade, com 10 votantes, até mesmo a ordenação de 19 opções tende a gerar apenas resultados cíclicos ${ }^{81}$.

Assim, é possível que a causa de um eventual aumento de instâncias em que decisões do STF sofrem da chamada dispersão de fundamentos pode ser atribuída ao fenômeno que discutimos na introdução. Se é verdade que, nos últimos anos, houve uma popularização da utilização da "declaração de nulidade parcial sem redução de texto", nos termos discutidos por Barroso ${ }^{82}$, esse resultado deveria ser previsível: afinal, se aceitarmos que um texto T tem $n$ interpretações possíveis, aumentamos drasticamente o número de alternativas que devem ser ordenadas pelos ministros ${ }^{83}$.

Isso pode ser atribuído diretamente à causa de pedir aberta: caso os ministros fossem obrigados a avaliar os argumentos levantados pelas partes, o número de fundamentações possíveis seria presumivelmente menor do que o número que a causa de pedir aberta permite. Imaginar um exemplo ajuda a tornar a discussão mais clara: suponhamos que A entre com uma Ação Direta de Inconstitucionalidade perante o STF. Ele aduz que a interpretação I da lei L é incompatível com a Constituição e pede que o STF declare a inconstitucionalidade dessa interpretação, declarando que a lei $L$ deve ser lida da maneira $I_{1}$ ou, alternativamente, da maneira $I_{2}$. Nesse caso, se algum ministro acha que $\mathrm{I}_{3}$ é melhor que as duas alternativas propostas pelo postulante, esse julgamento não poderia contar como fundamento para uma eventual decisão. Em outras palavras, a decisão nessa ADI não pode ser "L é constitucional se lida da maneira I 3 ". Por extensão, nenhum dos outros 10 ministros poderia oferecer a sua própria leitura preferida como uma das alternativas e, assim, reduziríamos drasticamente a probabilidade de que o resultado da decisão fosse cíclico.

\footnotetext{
${ }^{80}$ É necessário observar que os autores explicitam que esse é o pior cenário possível: assumindo probabilidades diferentes para cada uma das possíveis ordenações de preferência, é possível que existam mais resultados não-cíclicos. O resultado, porém, é relevante: mesmo que o arranjo de votação ofereça alguns resultados não transitivos, isso não parece ser o suficiente. Da mesma forma, assumir certas combinações de probabilidades pode afastar a incidência do teorema de Arrow (MORREAU, Michael. Arrow's Theorem. Stanford Encyclopedia of Philosophy, 2014. Disponível em: <https://philpapers.org/rec/MORAT>) por tornar o problema homogêneo. Como discuti anteriormente, porém, esse não parece ser o caso no âmbito do STF, que lida com questões moralmente complexas e que dividem a sociedade.

${ }^{81}$ KRISHNAMOORTHY, Mukkai S.; RAGHAVACHARI, Madabhushi. Condorcet winner probabilities - a statistical perspective. 2005. Disponível em: <http://arxiv.org/pdf/math/0511140.pdf> e NIEMI, Richard G.; WEISBERG, Herbert F. A mathematical solution for the probability of the paradox of voting. Behavioral Science, [s.l.], vol. 13, n. 4, p. 317-323. 1968, apontam a mesma tendência para o aumento de votantes. Como o incremento do número de ministros do STF não parece ser proposto por ninguém, nem considerado desejável empírica ou conceitualmente, não discutirei essa possibilidade.

${ }^{82}$ BARROSO, Luís Roberto. $\mathbf{O}$ controle de constitucionalidade no direito brasileiro: exposição sistemática da doutrina e análise crítica da jurisprudência. 6. ed. São Paulo: Saraiva, 2012.

${ }^{83} \mathrm{Não}$ se está defendendo a tese de que o direito é sempre radicalmente indeterminado. O ponto é apenas que quanto maior a possibilidade de interpretações possíveis para um texto, maior o número de alternativas que devem ser ordenadas pelos ministros.
} 
Da mesma forma, parece intuitivo dizer que textos mais indeterminados permitem mais interpretações do que textos mais determinados. Se esse é o caso e se combinamos esse fato com a existência da causa de pedir aberta, também devemos esperar um aumento nas votações cíclicas. Afinal, mesmo que a causa de pedir fosse aberta, mas $L$ só permitisse as interpretações $I_{1}$ e $I_{2}$, presumivelmente a deliberação do tribunal ficaria restrita a essas alternativas.

Em conclusão, é possível afirmar que, a não ser que estejamos dispostos a abrir mão de certos aspectos que consideramos importantes acerca do modo de deliberação típico dos tribunais (1a-5a ou 1b-4b), o fenômeno da dispersão de fundamentos sempre ocorrerá. Se isso é verdade, nossa melhor aposta está em tentar reduzir a quantidade de vezes em que ele ocorre. É possível que mudar a regra de contagem de votos seja capaz de fazer isso. Na falta de evidências sugestivas de que esse seja o caso, porém, penso ser mais prudente manter uma dose saudável de ceticismo e pensar em outras soluções mais robustamente comprovadas. Nesse sentido, é conceitualmente verdadeiro que reduzir o número de opções de fundamentação disponíveis reduz a quantidade de resultados cíclicos. Com base nisso, algumas estratégias para lidar com o problema se oferecem: 1) tornar o texto constitucional mais determinado; 2) defender a causa de pedir "fechada" e/ou 3) acabar com a "declaração de nulidade parcial sem redução de texto".

A primeira solução (1) é muito custosa: é difícil alterar o texto constitucional e torná-lo mais preciso envolve resolver questões moralmente controversas. Tornar o texto constitucional mais preciso pode, ainda, ser indesejável ${ }^{84}$. Defender a causa de pedir "fechada" parece um caminho mais promissor, mas também está sujeito a bons argumentos contrários. É possível, por exemplo, que vincular a decisão do STF no controle de constitucionalidade aos fundamentos levantados pela parte implicasse uma multiplicação da quantidade de ações desse tipo e a redução da segurança jurídica. Afinal, o STF poderia julgar uma ADI improcedente em um dia por não concordar com os argumentos das partes e, pouco tempo depois, julgar outra ADI sobre uma mesma lei procedente por um fundamento diferente. O juízo sobre a suficiência desse problema para o descarte da solução (2) envolve um debate mais amplo, mas é suficiente notar que, quaisquer que sejam os problemas dessa solução, ela parece ser eficaz para combater a dispersão de fundamentos.

Por fim, a solução (3) parece, ao mesmo tempo, eficaz e menos sujeita a contra-argumentos. Afinal, embora muito se discuta sobre o que é a declaração de nulidade parcial sem redução de texto, poucos argumentos normativos a favor da solução

\footnotetext{
${ }^{84}$ Nesse sentido, ver TUSHNET, Mark. Taking the constitution away from the courts. Princeton: Princeton University Press, 1999 e NAGEL, Robert F. The formulaic constitution. Michigan Law Review, Ann Arbor, vol. 84, n. 2, p. 165-212. 1985. De maneira mais geral, sobre a desejabilidade de regras relativamente indeterminadas ASGEIRSSON, Hrafn. On the instrumental value of vagueness in the law. Ethics, vol. 125, n. 2, p. 425-448. 2015.
} 
parecem convincentes no presente contexto. Se, como por vezes se argumenta, o objetivo é preservar a presunção de constitucionalidade das leis ${ }^{85}$, dificilmente podemos pensar em uma solução mais adequada: afinal, onde antes se utilizava a técnica da declaração de nulidade parcial sem redução de texto, agora simplesmente se julgará improcedente a ADI. Se, por outro lado, a ideia é maximizar concomitantemente a presunção de constitucionalidade e a prevalência de resultados justos, outros caminhos parecem igualmente promissores ${ }^{86}$.

\section{REFERÊNCIAS}

ALEXANDER, Larry. There is no first amendment overbreadth (but there are vague first amendment doctrines); prior restraints aren't "prior"; and "as applied" challenges seek judicial statutory amendments. Constitutional Commentary, Minneapolis, vol. 27, n. 2, p. 439-454, sept./nov. 2011.

ALEXANDER, Larry; SHERWIN, Emily. Demystifying Legal Reasoning. Cambridge: Cambridge University Press, 2008.

ALMEIDA, Danilo dos Santos; BOGOSSIAN, André Martins. "Nos termos do voto do relator": considerações acerca da fundamentação coletiva nos acórdãos do STF. Revista Estudos Institucionais, vol. 2, n.1, p. 264-297, jan./jun. 2016.

ARROW, Kenneth Joseph. A difficulty in the concept of social welfare. Journal of Political Economy, Chicago, vol. 58, n. 4, p. 328-346. 1950.

ARROW, Kenneth Joseph. Social choice and individual values. New York: Jon Wiley \& Sons, 1963.

ASGEIRSSON, Hrafn. On the instrumental value of vagueness in the law. Ethics, vol. 125, n. 2, p. 425-448. 2015.

BARROSO, Luís Roberto. $\mathbf{O}$ controle de constitucionalidade no direito brasileiro: exposição sistemática da doutrina e análise crítica da jurisprudência. 6. ed. São Paulo: Saraiva, 2012, p. 145.

BRANDO, Marcelo Santini; LEITE, Fábio Carvalho. Dispersão de fundamentos no Supremo Tribunal Federal. Revista Direito, Estado e Sociedade, Rio de Janeiro, n. 48, p. 139-166, jan./jun. 2016.

CHRISMANN, Pedro Henrique Veiga. Julieta não está pronta para ser Montecchio - A união das famílias jurídicas e a necessidade de uma nova metodologia do direito preocupada com precedentes. Revista de Direito Brasileira, São Paulo, vol. 14, n. 6, p. 03-17, maio/ago. 2016.

\footnotetext{
${ }^{85}$ SILVA, Virgílio Afonso da. Interpretação conforme a constituição: entre a trivialidade e a centralização judicial. Revista Direito GV, São Paulo, vol. 2, n. 1, p. 191-210, jan./jun. 2006.

${ }^{86}$ Ver, por exemplo, a ideia de inconstitucionalidade "as applied" (ALEXANDER, Larry. There is no first amendment overbreadth (but there are vague first amendment doctrines); prior restraints aren't "prior"; and "as applied" challenges seek judicial statutory amendments. Constitutional Commentary, Minneapolis, vol. 27, n. 2, p. 439-454, sept./nov. 2011.
} 
DWORKIN, Ronald. Taking rights seriously. Cambridge: Harvard University Press, 1978.

EASTERBROOK, Frank. Ways of criticizing the court. Harvard Law Review, Cambridge, vol. 95, n. 4, p. 802-832, feb. 1982.

KLAFKE, Guilherme Forma; PRETZEL, Bruna Romano. Processo decisório no Supremo Tribunal Federal: aprofundando o diagnóstico das onze ilhas. Revista de Estudos Empíricos em Direito, v. 1, p. 89-104, 2014.

KORNHAUSER, Lewis A.; SAGER, Lawrence G. Unpacking the court. The Yale Law Journal, Danvers, vol. 96, n. 1, p. 82-117. 1986.

KRISHNAMOORTHY, Mukkai S.; RAGHAVACHARI, Madabhushi. Condorcet winner probabilities a statistical perspective. 2005. Disponível em: <http://arxiv.org/pdf/math/0511140.pdf.>.

LIST, Christian. The theory of judgement aggregation: an introductory review. Synthese, vol. 187, issue 1, p. 197-207, 2012.

LIST, Christian; PETTIT, Philip. Aggregating sets of judgement: an impossibility result. Economics and Philosophy, Cambridge, vol. 18, n. 1, p. 89-110, apr. 2002.

LIST, Christian; PETTIT, Philip. Aggregating sets of judegements: two impossibility results compared. Synthese. vol. 140, issue 1, p. 207-235, 2004.

MEYERSON, Michael. The irrational Supreme Court. Nebraska Law Review, Nebraska, vol. 84, n. 3, p. 895-961, jul./sept. 2006.

MORREAU, Michael. Arrow's Theorem. Stanford Encyclopedia of Philosophy, 2014. Disponível em: $<$ https://philpapers.org/rec/MORAT>.

NAGEL, Robert F. The formulaic constitution. Michigan Law Review, Ann Arbor, vol. 84, n. 2, p. 165-212. 1985.

NIEMI, Richard G.; WEISBERG, Herbert F. A mathematical solution for the probability of the paradox of voting. Behavioral Science, [s.I.], vol. 13, n. 4, p. 317-323. 1968.

PACUIT, Eric. Voting methods. Stanford Encyclopedia of Philosophy, 2011. Disponível em: http://plato.stanford.edu/entries/voting-methods/.Visitado em: 25/01/2018.

ROSEVEAR, Evan; HARTMANN, Ivar Alberto; ARGUELHES, Diego Werneck. Disagreement on the Brazilian supreme court: an exploratory analysis. Disponível em: <http://papers.ssrn.com/ sol3/papers.cfm?abstract_id=2629329>. Acesso em 25 jan. 2018.

SCHAUER, Frederick. Formalism. The Yale Law Journal, Danvers, vol. 97, n. 4, p. 509-548. 1988.

SCHAUER, Frederick. Playing By The Rules: A Philosophical Examination of Rule-Based Decision-Making in Law and in Life. Oxford: Oxford University Press, 1991.

SCHAUER, Frederick. Precedent. In: MARMOR, Andrei (Org.) The Rouledge Companion to Philosophy of Law. New York: Routledge, 2012. 
SCHAUER, Frederick. Thinking like a lawyer. Cambridge: Harvard University Press, 2009.

SILVA, Virgílio Afonso da. Deciding without deliberating. International Journal of Constitutional Law, vol. 11, n. 3, p. 557-584, jul./sept. 2013.

SILVA, Virgílio Afonso da. Interpretação conforme a constituição: entre a trivialidade e a centralização judicial. Revista Direito GV, São Paulo, vol. 2, n. 1, p. 191-210, jan./jun. 2006.

SPECTOR, Hector. Constitutional choice, deliberation and Arrovian dictatorship. Palestra proferida no II Congresso Internacional de Direito Constitucional e Filosofia Política, na Escola Superior Dom Helder Câmara, na cidade Belo Horizonte, 26 nov. 2015.

TUOMELA, Raimo. Group reasons. Philosophical Issues, vol. 22, issue 1, p. 402-418, oct. 2012.

TUSHNET, Mark. Taking the constitution away from the courts. Princeton: Princeton University Press, 1999.

VOJVODIC, Adriana de Moraes; MACHADO, Ana Mara França; CARDOSO, Evorah Lusci Costa. Escrevendo um romance, primeiro capítulo: precedentes e processo decisório no STF. Revista Direito GV, São Paulo, vol. 5, n. 1, p. 21-44, jan./jun. 2009. 